\title{
Citizen Science Fiction: The Potential of Situated Speculative Prototyping for Public Engagement on Emerging Technologies
}

\author{
Jantien W. Schuijer (D) Jacqueline E. W. Broerse • \\ Frank Kupper
}

Received: 15 October 2019 / Accepted: 21 December 2020 / Published online: 13 March 2021

(C) The Author(s) 2021

\begin{abstract}
In response to calls for a research and innovation system that is more open to public scrutiny, we have seen a growth of formal and informal public engagement activities in the past decades. Nevertheless, critiques of several persistent routines in public engagement continue to resurface, in particular the focus on expert knowledge, cognitive exchange, risk discourse, and understandings of public opinion as being static. In an attempt to break out of these routines, we experimented with an innovative engagement format that employs situated speculative prototyping to support citizens in contextualizing and discussing developments regarding - in this casenanotechnology. This format invites participants to imagine and critically reflect on technological futures through collaborative prototyping and story-writing. In this paper, we outline five reconstructed contextualization patterns in which participants engaged during the format's exercises and use these to assess the value of the format in the current engagement landscape. We show that situated speculative prototyping has potential in the realm of informal public engagement initiatives, taking an explorative approach, but also warn of 'the designer fallacy' as a prominent pitfall of prototyping that could reproduce technoscientific framings and obstruct critical reflection
\end{abstract}

J. W. Schuijer $(\triangle)$ · J. E. W. Broerse · F. Kupper Athena Institute, BETA Faculty, VU University, Amsterdam, Netherlands on technological directions and implications if not treated with caution.

Keywords Public engagement (method) .

Speculative approaches · Prototyping ·

Nanotechnology $\cdot$ New and emerging technologies .

Responsible research and innovation

\section{Introduction}

The need for public dialog and inclusive deliberation on the social and ethical implications of emerging technologies is increasingly recognized [1]. Rapid developments in fields such as nanotechnology, biotechnology, cognitive science, and information technology have not only spurred enthusiasm about their potential to contribute to addressing major global issues, but have also raised concerns about unexpected and less desirable ways in which these innovations could affect our lives. Both technical uncertainties (e.g., gaps in empirical knowledge on effects, risks, and long-term impacts) and moral ambiguity (e.g., different views on what constitutes desirable impacts and acceptable risks) make it challenging to deal with new and emerging technologies in terms of policy-making [2]. This has fueled the development of frameworks like Responsible Research and Innovation (RRI) that encourage timely exploration of potential future impacts and scenarios, the exchange of perspectives among societal actors, and collective 
responsibility to steer research and development in both acceptable and socially desirable directions [3, 4]. Such inclusive exploration and deliberation may not necessarily result in consensus regarding actions to be undertaken-most probably they will notbut as Swierstra and Rip [5] point out, the added value of such undertakings resides in their capacity to stimulate reflexive awareness among actors, preventing dogmatic attitudes and strengthening resilience in the face of uncertainty.

Within the RRI framework, the inclusion of broader publics (e.g., 'citizens') in anticipation of and reflection on new and emerging technologies is actively promoted as a way to enrich, challenge, and broaden dominant technocratic visions of the future. Although RRI scholars have argued that such public engagement activities are meaningful only if they are explicitly coupled to policymaking structures [1], others have criticized excessive fixation on these 'formal forms' of public engagement. Selin et al. [6]) stress that 'imagining engagement as needing to be somehow related to decision-making and science governance ignores the ways that lay publics mostly engage in dialogue on science...' (p. 635). Just like Davies et al. [7], they continue to argue that informal engagement initiatives that do not directly feed policymaking processes have their own, more indirect ways, of stimulating inclusiveness in research and innovation. These scholars emphasize that informal engagement can be understood as capacity-building endeavors that contribute to citizens' individual learning, also empowering them to get involved in more formal engagement. Davies et al. [7] even argue that informal engagement activities often provide a better environment for individual learning, since there is more focus on exploration rather than on reaching consensus. Ultimately, it is the combination of both formal and informal engagement opportunities from which a culture of inclusion can develop.

Over the years, a broad range of formats has been developed to engage citizens formally and informally in group discussion on new and emerging technologies, including citizen juries, consensus conferences, focus groups, science cafés, and scenario workshops (for an overview, see [8, 9]; for recent examples of specific formats, see $[10,11])$. Despite this plethora of activities, we observe recurring criticism on a number of persistent routines in the nature of and approach to public engagement. A first critique applies to the focus on abstract reasoning and cognitive exchange of arguments in many public engagement activities. This focus is said to exclude people for whom such reasoning is difficult and to neglect other forms of expression, knowing and learning, such as story-writing, material engagement, or affective responses [6, 12-14]. A second critique relates to format structures that still engender hierarchical interactions, favoring expert knowledge over lay knowledge, for instance by starting a session with an expert presentation or focusing on expert-driven materials and scientific framings $[6,12,15]$. A third critique is that engagement activities often stick to 'traditional promises and risk discourses' (e.g., economic benefits, toxicity, safety measures) and thereby ignore reflection on broader ethical and social impacts of technology [8, p. 469, 16, 17]. Lastly, engagement activities still all too often treat public opinion as something 'fixed' that can be 'harvested'. Such an approach ignores the active character of sense-making and opinion-forming in engagement activities (for instance, the way in which opinions are shaped through interaction with other participants, the dialog format etc.) [6] and blinds us to context-dependent nuances that people make when trying to position themselves with regard to a relatively unfamiliar technology [18]. This critique is particularly relevant in the context of emerging technologies; owing to their complex, uncertain, and ambiguous character, developments are not always familiar to those participating in engagement activities, and sense-making as well as positioning should thus primarily take place within the dialogical spaces of the engagement event [19,20].

How, then, to provide a conversation environment that enables citizens to engage in the public deliberation of technological futures? We addressed this question in the context of a European RRI project called NANO2ALL. Here, we experimented with a dialog format that tried to break out of the traditional routines in public engagement to encourage discussion among citizens on the topic of nanotechnology. The format employed what we coin 'situated speculative prototyping' and was inspired by practices of design fiction [21-23] and speculative design $[24,25]$, as well as their application in participatory processes (see for instance 26-29, or work by the artist collective 'Extrapolation Factory'). As Auger (2013) argues, design fiction and speculative design have much in common, both using tangible prototypes (i.e., hypothetical objects) to instigate a process of inquiry and using fiction to open up one's imagination to 'alternative products, systems or worlds' (p.11). In creating our format, we specifically drew from the work 
of Heidingsfelder et al. [30], who employed speculative approaches in participatory design to stimulate discussion on emerging technologies. They make a case for the use of participatory design fiction elements, as it promises to: (1) foreground lay perspectives, by letting citizens - instead of (technology) experts-construct prototypes, as well as scenarios around them; (2) move beyond mere verbal forms of exploration and expression, by using physical materials to help people build and envisage future technologies; and (3) facilitate a process of inquiry and broader (ethical) reflection, by offering 'guided contextualization' (p.295) to link 'the technical' to 'the social'. Such context-based inquiry provides citizens the space to explore and construct a perspective towards nanotechnology developments within the engagement activity itself while allowing for contextdependent nuances in their positioning.

This paper aims to explore how situated speculative prototyping by citizens can help them to contextualize new and emerging technologies, such as nanotechnology. Here, we use the term 'contextualization' to refer to the process by which citizens make abstract technological notions more tangible and embedded in the social and cultural textures of our (future) society in order to make sense of ambiguous, uncertain, and complex technological futures from their own experience and perspective. Using empirical data from five NANO2ALL citizen dialogs across Europe, we reconstructed several contextualization patterns in which citizens engaged. We use these patterns to reflect on the potential advantages that participatory design fiction could offer in the context of public engagement and RRI, but also to highlight some of its pitfalls that-in our view-have remained underexposed in the literature to date.

\section{Methodology}

\section{Empirical Setting}

Our situated speculative prototyping experiment took place in the context of NANO2ALL, a three-and-ahalf-year dialog project aimed to enhance societal engagement in nanotechnology research and innovation. Since this 'technology' actually refers to a broad spectrum of activities that involve engineering at the scale of cells and molecules, it can be challenging to discuss the topic in public engagement events, making the need for guided contextualization even more pertinent [20]. NANO2ALL consisted of several rounds of dialog on nanotechnology, including a set of citizen dialogs that are central to this paper. The citizen dialogs aimed to explore societal needs, concerns, and values with respect to nanotechnology developments and were organized between April and June 2017 in five European countries: France, Italy, Poland, Spain, and Sweden. Each of the dialogs was hosted by a local learning institution (three science centers or museums and two research institutes) and facilitated by at least two staff members who were trained in the participatory design-fiction methodology. The dialogs were attended by 11-19 participants (in all age categories, ranging from one particular case in France where a mother brought her two children to participants who were well over 65 years old). The local institutions had recruited the participants for the citizen dialogs via their own communication channels. To prevent hierarchical communication dynamics favoring expert knowledge over alternative forms of knowing and understanding, we did not explicitly invite nanotechnology experts, nor did we present ourselves as such. However, considering the open character of the dialog sessions, there was no strict participant selection procedure. Consequently, there is a chance that some participants had a special affinity with the topic or possessed a certain (technical) expert perspective.

\section{The Dialog Format}

Our 4-h dialog format was inspired by Heidingsfelder's speculative approach to participatory design, which combines insights from research in design, innovation studies, and the social sciences (see [28, 30]). Although the original approach defined by Heidingsfelder et al. [30] encompassed several workshop sessions, the time and resource constraints in our project led us to focus mainly on two core elements of their approach: (1) collective prototyping and (2) collective story-writing with citizens to situate the prototypes in social-'everyday' — contexts. To facilitate the collection of data during the sessions, we added a plenary discussion exercise to the session structure in which participants reflected on the prototypes and stories. The three core activities (prototyping, storywriting, and plenary reflection) are further elaborated below. To concretize these activities and provide clear focus throughout the session, we decided to center each of the dialogs on one particular application field of 
nanotechnology: medicine (Sweden), textiles (Italy and Poland), and brain-computer interfaces (BCIs) (France and Spain). These application fields were chosen in close collaboration with the learning institutions themselves, taking into account (1) the national research context, (2) current public discourse in the country, and (3) the institutions' connections in the field.

\section{Prototyping}

After a general introduction to the dialog session, we invited participants in the first exercise to envisage the future of the introduced nanotechnology application field by working in pairs to physically build an object that they believed may be encountered in that future. Participants were provided with a diverse set of craft materials, a broad variety of inspirational and informational cards, both textual and visual (see Table 2 and Online Resource 1). Participants were able to choose for themselves which cards and craft material they wanted to use as a starting point for their prototype, allowing them the flexibility to focus on those aspects of nanotechnology that they considered relevant and interesting. In addition, the use of cards (which encompassed both technical details about nanotechnology, as well as more imaginative interpretations and lenses through which the topic can be explored) prevented us from centralizing expert knowledge or framing the dialog facilitators as nanotechnology experts.

\section{Story-Writing}

In the second exercise, participants worked in groups to envisage their prototypes' potential impacts (positive, negative, or ambiguous). They did this by writing or drawing short story fragments about the use of their object in a hypothetical social context (i.e., an 'everyday' situation). Many scholars have described the benefit of stories to engage people in anticipation and moral reflection in the context of new and emerging technologies [31-34]. Heidingsfelder et al. [30] argue that stories can help to contextualize abstract technological developments and "provide both accessible and appealing presentation formats and starting points for further practical and ethical considerations' (p. 295). Van der Meij et al. [32] add that by putting oneself into the shoes of a fictional character, people can explore future situations from a different perspective than their own, encouraging a reflective attitude.
We specifically chose to let participants write the story fragments themselves, instead of using prescripted vignettes. This allows participants to integrate personal experiences, thoughts, and feelings that are important in the process of reflection [32] and more readily invites participants to (re-)adapt story elements to explore new perspectives and dilemmas [34]. We provided participants with inspirational cards that contained a variety of story ingredients (see Table 2 and Online Resource 2) to help participants construct their story and challenge them to think of potential application contexts and impacts they had not envisaged when creating their prototypes. In constructing these story ingredient cards, we referred to STEEP factors (i.e., societal, technological, economic, environmental, and political factors), but also drew from the work of Boenink [35], who has outlined a (non-exhaustive) list of social-moral impacts of technology. These impacts are all grounded in historical knowledge on the dynamics between technology and society and aim to enrich the work of scenario developers.

\section{Plenary Discussion}

The final exercise encompassed a plenary discussion, in which the facilitator guided a group conversation in which participants expressed their needs, concerns, and values in relation to nanotechnology developments, based on the two earlier exercises. The inputs were collected in real time by the facilitator and written down on flip charts that were visible to the entire group. After a wrap-up of the plenary discussion, the session was closed and participants were asked to evaluate the session by filling in a questionnaire (Table 1).

\section{Data Collection}

We collected the following data:

- Audio-recordings of the plenary parts of the dialog sessions, which were transcribed in English.

- Materials produced by participants (prototypes, flip charts with needs, concerns, and values).

- Participants' answers to the evaluation questionnaire, translated into English.

- De-briefing conversations between ourselves (as the format developers) and the dialog facilitators, all of which were audio-recorded and transcribed. 


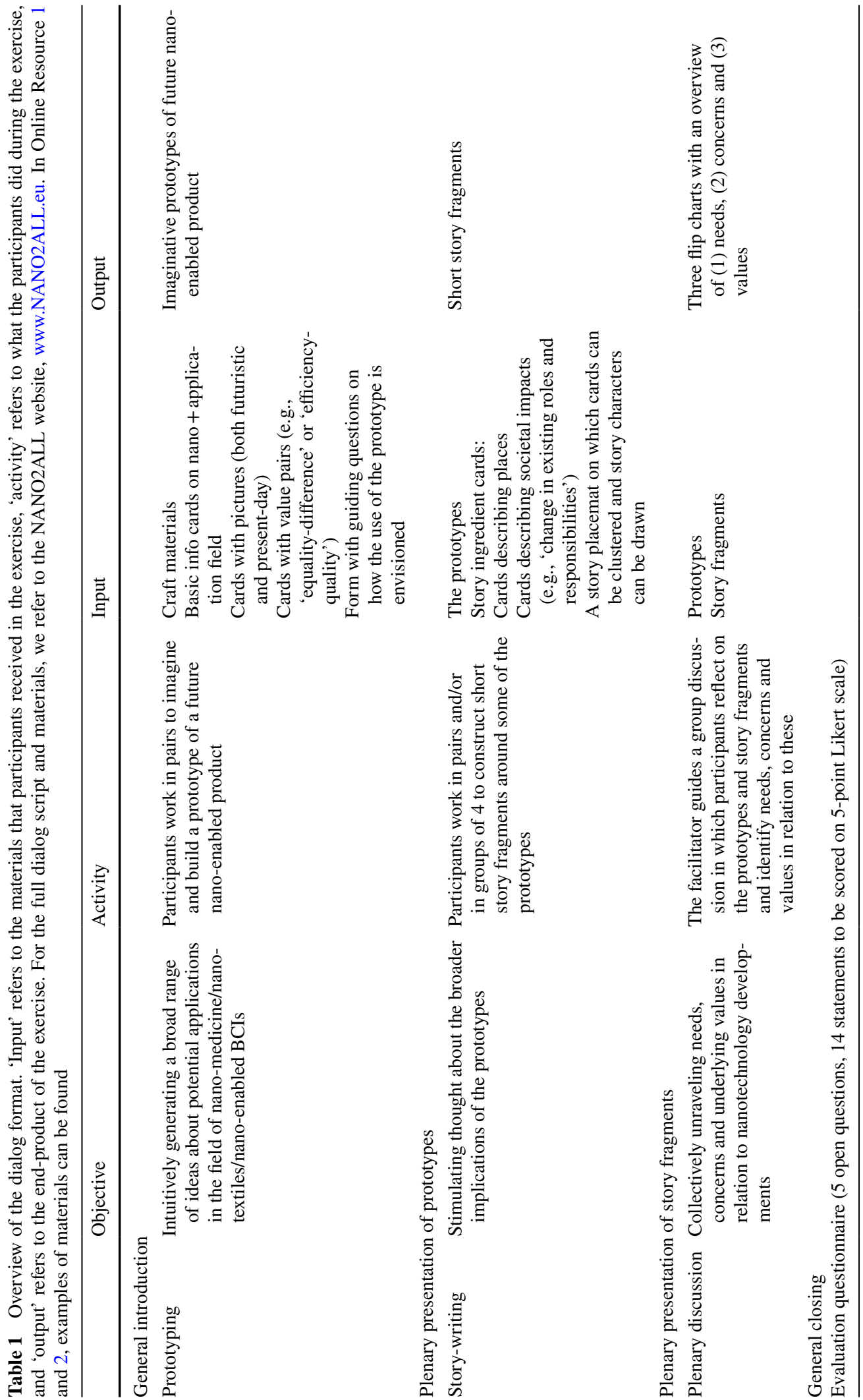


We used the transcripts of the dialog session as the most prominent source of information for our analysis, while the other sources were used to identify remarks and inputs relevant to our analytical focus on the process of contextualization.

\section{Data Analysis}

To facilitate the analytical process, we (as the format developers) familiarized ourselves with the dynamics of the format in practice by visiting three dialogs (France, Italy, Spain) as observers. Our analytical approach to the data was informed by thematic analysis [36] and we used MaxQDA [37] as an assistive analytical tool. Since four out of five transcripts did not identify which individual participant made which contribution to the discussion, but only distinguished between comments of the facilitator and those of a participant, we performed an analysis that focused on general group patterns, rather than one that detailed the development of and dynamics between individual perspectives. Eventually, we constructed analytical themes that represent general patterns of how participants tried to contextualize nanomedicine/nanotextiles/ nano-enabled BCIs within our dialog format, i.e., 'contextualization patterns'. We focused on patterns of contextualization that recurred throughout the data set. Although we would describe our analyses as inductive, in which we really started out with identifying codes and themes that were strongly linked to the data [36], some alternation and iteration between inductive and deductive coding took place at later stages of the analysis, when codes had to be clustered or renamed, or subthemes had to be specified.

\section{Results}

In our interpretative analysis of the dialog discussions, we reconstructed five interconnected contextualization patterns in which participants engaged: (1) exploring applications and functionalities, (2) making problem-solution linkages, (3) embedding prototypes in social situations, (4) exploring concern about social impact, and (5) drawing comparisons. To provide a better understanding of the dialogs' conversational texture throughout the result section, Table 2 presents an overview of all the prototypes that were created during the dialog sessions. We also incorporate a brief overview of the initial dialog evaluation to sketch how the format was received by the participants themselves.

\section{Exploring Applications and Functionalities}

This contextualization pattern was most prominent in the prototyping phase of the dialog, in which participants actively read through the informative and inspirational material to imagine a nanoenabled object of the future. When looking at the type of applications that participants imagined, and the functionalities that they integrated in their prototypes, we observed-in all dialogs-a curiosity for nano-enabled functions that allow for 'measuring' or 'monitoring' of substances and activity (e.g., in the body, environment). An example of such a device was the 'Baby Friend', a baby suit made out of nano-textiles that can measure all kinds of bodily parameters. The participants who created this device explained:

It could be useful at home, in the nursery school or kindergarten. It will communicate for example: 'I'm cold', warming simultaneously; or 'hug me', 'I'm hungry', 'I'm thirsty', 'I'm sleepy'. If the baby is sweating, the body friend device knows it as well and controls their body temperature. In general, it takes care of the kid's safety and comfort. Additionally, it communicates the level of stress of the little one. [Poland].

This description also illustrates how participants often linked measuring/monitoring function to warning systems for the user (in this case, the parents), or active intervention mechanisms that operate without the user being aware of it (in this case, controlling body temperature). Particularly, the 'invisible' character' of nanotechnology seemed to play a role here, allowing to fix or normalize a situation without requiring the user to undertake a specific action.

Apart from the general pattern across all dialogs to explore applications that could measure/warn/ intervene, explorations of other nano-enabled functions seemed more closely linked to specific 
Table 2 Overview of the prototypes that were built in each of the dialog sessions. See Online Resource 3 for exemplary pictures of the prototypes

\begin{tabular}{|c|c|}
\hline Prototype & Explanation \\
\hline \multicolumn{2}{|l|}{ Sweden-nano-medicine } \\
\hline Nano tooth substance & $\begin{array}{l}\text { A substance that can be injected into the teeth and creates permanent protection that makes } \\
\text { brushing the teeth superfluous }\end{array}$ \\
\hline Doctor Plupp & $\begin{array}{l}\text { A device specifically developed for children that detects and restores vitamin and mineral } \\
\text { deficiencies }\end{array}$ \\
\hline Optical nerve fix & $\begin{array}{l}\text { Injection with a substance that can heal a damaged optical nerve and thereby treat people } \\
\text { who suffer from this form of blindness }\end{array}$ \\
\hline Dr. Relief & $\begin{array}{l}\text { A tiny device in the body that can measure pain and administer pain killer, both very locally } \\
\text { in the body }\end{array}$ \\
\hline Nano vacuum cleaner & $\begin{array}{l}\text { A small nanorobot that can detect plaques in the brain and absorb or dissolve them to cure } \\
\text { Alzheimer's disease }\end{array}$ \\
\hline \multicolumn{2}{|l|}{ Italy-nanotextiles } \\
\hline Textile exo-skeleton & $\begin{array}{l}\text { Light, flexible, but resistant textile suit that can be controlled by a "central station" that } \\
\text { sends out electrical pulses. The suit can help people who have difficulty with walking and } \\
\text { moving or can support people who perform heavy physical labor }\end{array}$ \\
\hline Geoscreen safe and control & $\begin{array}{l}\text { A nanotextiles glove that is connected to all satellites, and can communicate sensations of } \\
\text { what is happening at different places on earth (e.g., humidity, volcanic activity) }\end{array}$ \\
\hline Medical clock & $\begin{array}{l}\text { A nano tissue with a clock that can interact with the skin to measure bodily functions, send } \\
\text { out warnings, and allow for programmed release of nano-encapsulated drugs, which may } \\
\text { help those who tend to forget to take their medication }\end{array}$ \\
\hline Clean-up textile & $\begin{array}{l}\text { A nanotextiles that is self-cleaning, anti-bacterial, easy to iron, quick to dry, and can be } \\
\text { used in many settings (e.g., as a table cloth in restaurants) }\end{array}$ \\
\hline Electro-magnetism filter & A nanomaterial that filters electromagnetic waves and can be used in day-to-day clothing \\
\hline Clean and smell & $\begin{array}{l}\text { A nanotissue that can be put over interior decoration items (e.g., sofas, carpets) and absorbs } \\
\text { and transforms dirt particles into good smell }\end{array}$ \\
\hline Lumi tissue & $\begin{array}{l}\text { A clothing textile that protects the skin and emanates light at different intensities, depend- } \\
\text { ing on the ambient light }\end{array}$ \\
\hline Seat, safe, and relax & $\begin{array}{l}\text { An antibacterial and self-cleaning seat lining that can be used in public transportation. It } \\
\text { neutralizes harmful particles, prevents transpiration, and is equipped with a device for } \\
\text { aroma therapy and listening to music }\end{array}$ \\
\hline Mapite & $\begin{array}{l}\text { A one-size fits-all fabric that can be used as a hat, sock and glove and provides a protection } \\
\text { layer in all kinds of situations. The fabric is anti-bacterial, anti-infection, water repellent, } \\
\text { fire-proof, breathable, self-heating and elastic }\end{array}$ \\
\hline \multicolumn{2}{|l|}{ Poland-nanotextiles } \\
\hline First aid blanket & $\begin{array}{l}\text { A blanket that is used in hospitals and ambulances to protect patients, detect injuries and } \\
\text { monitor certain bodily parameters }\end{array}$ \\
\hline Intelligent curtain & $\begin{array}{l}\text { Curtain made of smart textile that can change color, regulate lightning and room tempera- } \\
\text { ture and is self-cleaning }\end{array}$ \\
\hline Baby friend & $\begin{array}{l}\text { Baby clothing that can measure bodily parameters and mood of the baby and communicates } \\
\text { this information to parents using an mobile app }\end{array}$ \\
\hline Underwear for allergy sufferers & Underwear that diagnoses and treats allergies \\
\hline Skin shaper & Artificial layer of skin that can reshape your silhouette or face \\
\hline Sport suit & Protective suit that monitors bodily parameters during sports and prevents sports injuries \\
\hline Liquid "nice to catch" & Waste compressing material that fights bad smells and degrades waste \\
\hline Net fibers used in architecture & $\begin{array}{l}\text { Nano fibers that strengthen architectural structures, making it possible to preserve old } \\
\text { buildings for a longer time }\end{array}$ \\
\hline First aid blanket & $\begin{array}{l}\text { A blanket that is used in hospitals and ambulances to protect patients, detect injuries, and } \\
\text { monitor certain bodily parameters }\end{array}$ \\
\hline
\end{tabular}


Table 2 (continued)

\begin{tabular}{|c|c|}
\hline Prototype & Explanation \\
\hline \multicolumn{2}{|c|}{ France_-nanotechnology-enabled BCIs } \\
\hline Artificial eye & $\begin{array}{l}\text { An artificial eye that is connected to the brain with sensors to restore the vision of those } \\
\text { who suffer from blindness }\end{array}$ \\
\hline Memory restorer & $\begin{array}{l}\text { This prototype consists of two elements: (1) the use of nanotechnology to restore the con- } \\
\text { nectivity between brain synapses in people whose memory is starting to fail and (2) the } \\
\text { insertion of a chip with important information about one's life in the brain of people who } \\
\text { already lost their memories }\end{array}$ \\
\hline Stroke sensor & $\begin{array}{l}\text { A sensor that is attached behind the ear, which can detect signs of an imminent stroke and } \\
\text { automatically warn an ambulance }\end{array}$ \\
\hline Neuro-trans-mission flower & $\begin{array}{l}\text { A device that enables information exchange between two brains, by using nanoparticles to } \\
\text { extract information from one brain, communicate it to a flower-shaped device, which uses } \\
\text { nanoparticles to transfer the information to another brain }\end{array}$ \\
\hline Playstation Nano-Bidi & $\begin{array}{l}\text { A nano-sensor device that allows a player of a video game to experience the emotions and } \\
\text { sensations of a game character, and similarly allows the game character to evolve based } \\
\text { on the real emotions of the player }\end{array}$ \\
\hline \multicolumn{2}{|c|}{ Spain—nanotechnology-enabled BCIs } \\
\hline Emo-experience & $\begin{array}{l}\text { A helmet with brain electrodes that can be connected by cable to objects such as books and } \\
\text { paintings. The device allows you to live more deeply what you are seeing, e.g., feeling the } \\
\text { emotions of a story character, or tasting the flavors of food that is described }\end{array}$ \\
\hline Telepathic ring & $\begin{array}{l}\text { An (ear)ring that can read brain waves and allows you to communicate telepathically with } \\
\text { others, not only sending verbal information, but also sensations and images. The ring } \\
\text { is connected to your phone and here you can select with whom you want to share your } \\
\text { information }\end{array}$ \\
\hline Nutritional controller & $\begin{array}{l}\text { A biosensor in the blood that measures your nutritional levels and communicates this to a } \\
\text { mobile app. The sensor can also connect to fridges at home or in the supermarket, which } \\
\text { can then suggest which specific products you should pick at that moment in time }\end{array}$ \\
\hline Inter-communicator & $\begin{array}{l}\text { A nano-enabled device for people who suffered from brain injury. It stimulates neurons } \\
\text { near the damaged area that are not used effectively to restore the brain's functionality }\end{array}$ \\
\hline Smart safety glasses & $\begin{array}{l}\text { A chip in the brain that can measure someone's level of attention. The chip is connected } \\
\text { to a pair of glasses that produces a warning signal if your level of attention is too low to } \\
\text { perform a certain task (e.g., driving a car, performing surgery) }\end{array}$ \\
\hline Relationship facilitator & $\begin{array}{l}\text { A device that supports social interaction in conflicting situations. It consists of a brain } \\
\text { implant and a ring with an interface. The implant captures emotions and sensations via } \\
\text { electrical signals from the brain and translates these in a clear message to the other person }\end{array}$ \\
\hline
\end{tabular}

dialog topics, e.g., the use of nano structures to restore damaged human tissue (in dialogs on nanomedicine and nano-enabled BCIs), or protective and self-cleaning functions of nano-materials (in dialogs on nano-textiles). In the latter, we also observed remarks about the environmental friendliness of the created devices, although mostly as an aside, not as the devices' main purpose.

\section{Making Problem-Solution Linkages}

Already in the prototyping phase, we observed a strong tendency for participants to position their prototypes as a solution to a particular problem.
This tendency was also observed among several of the dialog facilitators. The problems varied in magnitude, from major challenges that the world is currently facing (e.g., waste processing, Alzheimer's disease) to small day-to-day problems that would be convenient to resolve (e.g., sports injuries, communicative tensions in relationships). Sometimes, explicit links were made to local or personal realities (e.g., a recent accident that happened in the region, a friend who fell ill, problems with maintenance of old flats in the city). Across all dialogs, we observed particular attention to problems related to 'health' and 'quality of life'. This was not restricted to those dialog sessions that focused 
on nano-medicine (for which it seems obvious that the health theme takes a central position), but was also observed in the sessions on nano-textiles and BCIs. In each of the dialogs, participants linked nanotechnology to hypothetical applications that could effectively diagnose and cure diseases, recover lost functionalities, silently treat chronic conditions, or stimulate healthy lifestyles. When presenting their nanotechnology prototypes and story fragments, some participants stressed how the use of the hypothetical device would allow those who suffer from a medical condition to participate again in their daily (social) activities, and thereby 'recover the joy to live' ( $\mathrm{P}$, Spain). As one of the participants in the Italian nano-textile dialog indicated:

The central point of everything is always health, anyway. The research that is carried out usually has the effect that people feel better, in all aspects [...].

Participants' tendency to focus on 'technology as a solution' was also illustrated in the character of the story fragments that participants created in the second exercise of the dialog. Many of the fragments had the character of technological success stories, presenting a 'problem—use of technology_problem resolved' storyline. Those participants who did not refer to any kind of problem that they wish to resolve in their presentation of their device prototype sometimes still transformed their device into a solution during the story-writing phase. For example, the EmoExperience, a hypothetical BCI that allows you to feel the emotions of game/video/story characters, which participants initially developed for entertainment purposes, but in the story-writing exercise became a tool to support educational practices. Thus, a rather positive image of technology was sketched in the story fragments. In many cases, critical reflection of and attention to potential undesirable impacts entered the story only in the plenary discussion phase, when the facilitator would actively ask for concerns and collective reflection on broader effects of the devices' application.

\section{Embedding Prototypes in Social Situations}

The embedding of prototypes in social-'everyday' contexts was a process that occurred throughout the entire dialog session. Already while building a prototype of their nano-enabled device, participants simultaneously envisaged potential user groups and particular settings in which their device could be employed. Participants often shared these considerations in presenting their prototype to the rest of the group, sometimes providing even more detailed and tangible examples to help others understand in what way their device could function. Context descriptions often became more detailed during the story-writing and plenary discussion phase of the dialog. In this section, we describe two sub-patterns that we observed with respect to the embedment of prototypes in social contexts.

\section{Linking Prototypes to Story Characters in a Particular Situation}

Particularly in the story-writing phase of the dialog, participants made links between the use of the hypothetical devices and story characters (e.g., Antonio, the forklift truck driver; Zbyszek, the lawyer, who is passionate about sports; Kim, the cook in a restaurant). This forced participants to not only describe their devices in terms of their functionality or usefulness in particular situations, but to attribute a specific meaning to the device through the eyes of a character. One participant, for instance, said:

We have imagined 15-year-old Ania. She's an example of a schoolgirl that likes being active. She dreams of being a professional sportswoman. Ania is happy to spend her time with friends, she does not feel like being an allergic even tough she is one. Special underwear protects her from unpleasant consequences of allergy. She visits her doctor this afternoon for checking how her system reacts to new medication. Ania can bike freely and she likes it. Since she started using antiallergenic underwear her health has been significantly better. The girl plans to become a professional sportswoman and allergies don't limit her choice of future profession. [Poland].

The example shows how this device is contextualized by linking its use to a character with a name (Ania), who has particular intentions to use the device (dream of becoming a sportswoman, spending time with friends) and also experiences the effects of employing the 
device (feeling as though her allergies no longer limit her dreams and activities). Linking prototypes to story characters thus helps participants to unravel the personal, social, and cultural meanings of technology in a context.

Unraveling the meaning of a technology in relation to specific characters who find themselves in a specific situation also encouraged participants to ask further questions about the desired forms of prototype use and implications for an individual. In the Swedish dialog, for example, participants imagined a device that could regulate experienced pain levels. In a story fragment, participants connected the use of their prototype to Bertill Bertillson, who suffered from chronic pain, but wanted to go to a party.

Well of course it has effects on the health if you have this pain-killing device. That you actually may say yes, and go to a party instead of staying home. And then you must take in consideration the changes in roles when you have to be responsible for being sick although you don't feel it. He will have to think about the way he lives his life, when he works with such a machine in his body. [P, Sweden]

\section{Shifting Between Contexts and Creating Alternative Story-lines}

Throughout the dialog, participants played around with different contextual factors to explore new meanings and implications of their imaginary nano-enabled devices. Sometimes, this already happened at early stages of the dialog, when participants presented their prototypes and shortly later mentioned in what contexts they could see their device being functional.

This kind of sports suit could be used by mountain rescuers and paramedics. Firefighters and police officers work in extreme conditions as well, so this product is for them as well. [P, Poland]

Many participants used the story-writing exercise to explore a new application context, and also the plenary discussion on needs, concerns, and values sometimes triggered these contextual shifts. In the plenary discussion of the Spanish dialog, for example, participants further explored new fields of application for the earlier mentioned
Emo-Experience device, besides entertainment and educational support:

P: It could also be used to treat people who have suffered a trauma [...] because, well, it allows, well, empathy to transmit a series of feelings. I'm referring a bit to the hypnosis.

Facilitator: Are we changing the application?

Correct?

[...]

$P:$ We are changing the context.

Facilitator: This is psychology now, psychotherapy.

P: Psychotherapy, yes.

Participants not only used contextual shifts to explore new opportunities for their prototype, but also to identify potential harmful applications. A little later in the conversation about the Emo-Experience, participants, for instance, expressed concerns about the device being used in a different way than intended; those in power (government, advertisers) may employ the device to manipulate our feelings towards products or (political) ideas:

It already exists today, now. Instead of informing us, they cultivate us, they tell us what we have to think, what we have to be worried about, and what we should do to solve it. [P, Spain].

Contextual shifts thus help to highlight other (and still undiscussed) ways in which the technology might interact with societal structures and powers-both desirably and undesirably - and also create room for critical reflection on those very structures and powers.

Other participants would not introduce an entirely new application context to the discussion (e.g., from entertainment environments to psychological treatment to commercial/political indoctrination), but integrated alternative storylines or story-endings in the existing story and prototype contexts, allowing them to ask 'what if...?' questions. For instance, participants in the Swedish dialog created a device that could diagnose certain deficiencies and health markers in the body. In the plenary discussion, a fellow participant asked:

P: But it will identify all diseases too, this gadget?

P: Well, let's say that it can register a few health markers. 
$P:$ But if it identifies some strange form of cancer that costs a fortune to treat? Costing millions per year just for the medicine?

Here, the introduction of a 'what if..?' scenario introduces a new dilemma that helps to make sense of the kind of situations that could arise if this device were used in practice, depending on its interaction with the specific societal system in which the technology is imagined to operate.

\section{Exploring Societal Concerns}

In many dialogs, questions of concern about the prototypes and their application would only arise in the later stages of the dialogs, mainly during the plenary session that guided the participants towards reflecting on a broader variety of societal impacts of their prototype. First, participants expressed concern about the feasibility of the technological promise: what if the device does not work as it is supposed to? In addition, two concerns were frequently drawn upon: (1) imbalances in power, access, and distribution of benefits and (2) tensions with respect to safeguarding human identity.

With respect to the first, participants expressed their concern about the costs of nano-enabled products, 'technocratic elitism' [P, Italy] and only 'those with means [having] access [to the products of science]' [P, France]. Some participants pondered about the social effects of unequal access to nanoenabled products, e.g., 'If this wonderful remedy is not accessible to everyone then the inequalities will grow even more' [P, Sweden], and others mentioned concerns about the influence of economic interests on technological development. Many plenary conversations also focused on the potential abuse of nano-enabled devices by those in power or having bad intentions (e.g., governments, terrorists, hackers).

With respect to the second point, participants referred to three different areas of tension: dependence versus autonomy, perfection versus human dignity, and human versus artificial. With respect to the first, we noted on the one hand an interest in technologies that could measure (bodily) signals and immediately intervene (e.g., heat the body, send out an alarm to medical professionals, deliver substances), making it easier to participate in social life autonomously without worrying about one's condition. On the other hand, participants also expressed concerns about too much delegation of responsibilities to technology, sometimes integrating specific options for control in their prototypes from an early stage in the dialog (e.g., having to press a button to set an intervention into motion) or stressing that individuals should have the freedom to choose whether they want to use a particular device. Participants pondered how 'dependence on technology' [P, Italy] and how its convenience could make us ignorant of underlying problems. Second, some participants recognized a striving for perfection in the prototypes and story fragments that were created in the dialogs and expressed concern about how the constant search for our improvement might influence our human dignity:

I think that we have the same ideas and values with all these gadgets, that everyone shall live a life free of pain and problems. [...] I mean if everyone has no pains or disease, say that everybody is in top condition, in memory and body and can live a hundred years. There will surely come other problems instead. We will have problems with our feelings and our spiritual inner life. [P, Sweden].

The final tension, human versus artificial, resonated most prominently in the dialogs on BCIs. Here, participants contemplated how nano-enabled devices that interact with the brain could produce 'super humans' who perform 'above average' [P, Spain], blurring boundaries between man and machine, or 'reality and fiction' [P, France].

It seems to me that there should be a threshold that should not be passed, to keep them like a man, like their fellow beings, not a machine. And I'm not sure where these thresholds are. [P, France]

\section{Drawing Comparisons}

A fifth contextualization process in which participants engaged was the drawing of comparisons to connect imaginations of the future to current realities or collective understandings. Throughout all stages of the dialog, participants referred to other technologies, current practices, and even science fiction to make future products and situations more tangible. In the object-building phase, comparisons were often used 
to illustrate how hypothetical devices would work in the future:

\section{$P:$ I understand that medication is done through skin somehow. Underwear releases drug? \\ P: Yes, it can do it. \\ $P$ : Reminds me a bit of a transdermal contraceptive patch. So, this underwear is healing but more naturally because it does not provide some extra chemical substances. \\ [Poland].}

In the story-writing phase and plenary discussion, comparisons with other technologies helped participants to make sense of potential broader impacts of the objects' use or to predict possible social practices arising from their devices:

You mentioned before... ehm... genetic modifications: let's be honest, it's always... it's always... famous multinational companies that are interested in checking where it's more interesting to make modifications and improvements: not where there's more necessity for them, but where there's more economic interest. [P, Italy].
In some cases, the introduction of a comparison could steer the discussion away from the topic of nano-enabled devices, not explaining why a particular comparison was introduced and elaborated on.

\section{Initial Evaluations of Participants}

Participants' responses to the evaluation questionnaire show a very positive experience of the event (see Table 3). In answer to the open-ended questions, participants referred to the value of exchanging thoughts with others and the use of simple materials to create an idea or scenario. Indicating what they learned or realized during the dialog exercises, many participants referred to awareness of either the possibilities of nanotechnology, related concerns or both of these, as well as the realization that there are different perspectives toward this emerging technology. Several participants mentioned that they would have liked to receive more information about the state of the art of nanotechnology, its hazards, and legal aspects. In addition, some participants noted that environmental impacts of nanotechnology remained under-discussed in their dialog session.
Table 3 Outcome evaluation questionnaire. The questionnaire was filled in by 68 (97\%) of the participants. Participants scored statements on a 5-point Likert scale $(1=$ totally disagree, $5=$ totally agree). The table only shows the total average scores, lowest average score among the 5 dialog sessions, and highest average score among the 5 dialogs. No further statistical analyses were carried out

\begin{tabular}{|c|c|c|c|}
\hline Question & $\begin{array}{l}\text { Total aver- } \\
\text { age score }\end{array}$ & $\begin{array}{l}\text { Lowest aver- } \\
\text { age score }\end{array}$ & $\begin{array}{l}\text { Highest } \\
\text { average } \\
\text { score }\end{array}$ \\
\hline 1. The given information on [topic] $]^{\mathrm{a}}$ was understandable & 4.35 & 4.00 & 4.81 \\
\hline 2. It was clear to me what was expected of us in the dialog exercises & 4.05 & 3.50 & 4.64 \\
\hline 3. The structure and set-up of the session helped me to imagine the future of [topic] & 4.12 & 3.75 & 4.50 \\
\hline 4. The interaction with other participants helped me to shape my own ideas and opinions & 4.07 & 3.50 & 4.69 \\
\hline 5. My input was respected by others & 4.56 & 4.30 & 4.83 \\
\hline 6. I felt free and safe to develop my own ideas in the exercises & 4.60 & 4.27 & 4.75 \\
\hline 7. I felt engaged to participate actively throughout the exercises & 4.57 & 4.14 & 4.72 \\
\hline 8. The dialog session enabled me to explore multiple views on the topic & 4.24 & 4.00 & 4.45 \\
\hline 9. I was able to contribute as I wished & 4.29 & 4.17 & 4.50 \\
\hline 10. The exercises stimulated me to generate creative ideas & 4.29 & 3.91 & 4.69 \\
\hline 11. I gained new insights in my own ways of thinking & 3.66 & 3.00 & 4.06 \\
\hline 12. The event was well organized & 4.60 & 4.27 & 4.72 \\
\hline 13. The creative exercises helped me to express my needs and concerns regarding [topic] & 4.00 & 3.73 & 4.31 \\
\hline 14. I feel that the people running the event were neutral & 4.37 & 3.88 & 4.75 \\
\hline
\end{tabular}

${ }^{\mathrm{a}}$ Topic $=$ nano-medicine, nanotextiles, or nanotechnology-enabled BCIs 


\section{Discussion}

We started this article by presenting critiques of persistent routines in public engagement activities and suggested the use of situated speculative prototyping as a way to do things differently, i.e., moving beyond a mere focus on abstract cognitive forms of reasoning, traditional promise-risk discourses, and the favoring of expert-driven perspectives, as well overcoming simplistic understandings of public opinion as being static. In our engagement experiment, we explored how participants contextualized nanotechnology when working with the situated speculative prototyping format and presented five interconnected contextualization patterns in which they engaged: (1) exploring applications and functionalities, (2) making problem-solution linkages, (3) embedding prototypes in social—'everyday'—situations, (4) exploring societal concerns about applications, and (5) drawing comparisons. In what follows, we highlight several observations-in terms of the format's potential and pitfalls - to reflect on its value in supporting citizens to contextualize abstract technological notions and to assess its contribution to the field of public engagement and RRI in general.

\section{Potential of the Format}

Besides providing participants a positive experience, our analysis showed that our situated speculative prototyping format has several strengths that could be valuable in the current engagement landscape. The format sparked discussion about potential opportunities of nanotechnology (e.g., improving health or quality of life), but was also able to draw participants into reflection on broader ethical and social issues, such as the effect of nanotechnological applications on the growth of power imbalances, unequal access to technological solutions, or people's sense of responsibility and human identity. In this respect, the format allowed participants to move beyond the conventional promise-risk discourse around nanotechnology that has been criticized by various scholars $[8,16,17]$.

Our analysis further indicates that participants actively explored different perspectives towards nanotechnology and context-dependent meanings. The social situations that were sketched in the story-writing exercise seemed to aid participants in the last phase of the dialog to play around with fictional settings and envisaged outcomes of a prototype's use, thereby unfolding new understandings of the devices and postponing unproductive judgments in dichotomous terms of technological acceptance and rejection [18].

The use of physical material and story-writing showed potential to escape mere cognitive and detached forms of reasoning. When considering the physical work with prototypes, for instance, participants did not have to explicitly verbalize aspects of nanotechnology that attracted their attention (positively or negatively), but could integrate functionalities in their prototypes that intrigued them (e.g., monitoring+immediate intervention). The prototypes themselves thus became a form of expression, evoking new questions from other participants throughout the dialog (e.g., Can it also do this, or that? Because if that is the case, then...) or highlighting certain dilemmas, such as those related to the delegation of responsibility to technology (e.g., should we add a control button for the user?). In addition, story-writing allowed participants to engage with the more complex emotional-moral [14] dimensions of reflection on sociotechnical futures, preventing mere detached forms of reasoning. Participants described inner worlds of story characters in relation to the use of their hypothetical devices, opening up the conversation to the exploration of human struggles, hopes, and fears. In the plenary discussion, participants also used alternative story-lines or questions about the scenario to give expression to their own hopes and fears for the future. It is this ability of both objects and stories to invoke questions and re-imagination of technological futures that has been welcomed as a tool to stimulate broader reflection on technological practices in recent innovative engagement initiatives, see, e.g., [38].

Lastly, our experience with the format suggests that is also has potential for qualitative data collection on citizen perspectives and positioning towards new and emerging technologies. In the case of the NANO2ALL project, we used the prototypes, stories, and plenary exchanges as data sources to enrich discussions and reflections of stakeholders involved in nanotechnology governance. In presenting the outcomes of the dialogs, we wanted to account for context-dependent nuances in participants' positioning. Therefore, we did not list a set of dry needs, concerns, and values, but integrated the data in six visual and ambiguous scenarios (see [39]). 


\section{Dealing with Potential Pitfalls of the Format}

Some of design choices that we made to break out of unproductive routines in public engagement simultaneously introduced new pitfalls that should be approached with care when applying situated speculative prototyping in future initiatives. First is the potential reproduction of expert-driven perspectives in the dialogical exchanges. Although our format intentionally foregrounded citizens' perspectives, our analysis showed that dominant techno-scientific framings, emphasizing progress and control $[2,40]$ still heavily echoed through participants' contextualization efforts, particularly in the first two stages of the dialog (prototyping and story-writing). The pattern of making problem-solution linkages is quite illustrative in this sense, with participants framing their prototypes as a solution to an existing problem and embedding their prototypes in technological success stories. Moreover, we observed that some participants actively sought expert perspectives, e.g., by asking for more technical information before wanting to prototype or referring to the need for an expert's opinion about the technical feasibility of their prototype. The request for more technical information expressed by some in the evaluation questionnaire is in line with such remarks.

These observations are not particularly surprising given that techno-scientific narratives are powerfully ingrained in our culture and social structures [2]. Especially in contexts of uncertainty and unfamiliarity, people use these broader narratives and cultural understandings as a resource to make sense of the unknown [40-42]. The fact that our dialogs took place in locations like science centers and were attended by self-assigned participants, who probably had a particular interest in technology and expectations of a sciencecenter event, may have strengthened this dominance even further. Our participatory design-fiction format may also have had an influence. Being put in the role of a designer, it feels only natural to create a device to solve a particular problem, since this is the dominant way in which technological development processes are portrayed. Moreover, as a designer, you become enthusiastic about your idea, which creates a blind spot regarding concerns and negative impacts. This may have made our participants prone to what Ihde [43] coined 'the designer fallacy' and is particularly problematic when considering the intended purpose of our prototyping and story-writing: facilitation of broader reflection by making technology and its impacts more tangible and imaginable.

Our analysis showed, though, that the designer fallacy can be overcome by purposefully guiding participants into a critical mode. Facilitators actively invited participants to reflect on potential concerns in the plenary discussion phase of our dialog, and this encouraged participants to further contextualize their prototypes, embedding them in new social scenes with a greater emphasis on potential ambiguities and concerns. This resulted in increased prominence of 'counter narratives', i.e., imaginaries that reject dominant techno-scientific framings, and stem from broader concerns in Western societies about the influence of technology on our lives [40]. In the expressed societal concerns regarding power, equality, and distribution of benefits, for instance, we strongly recognize counter narratives that Davies and Macnaghten [40] coined 'the rich get richer and the poor get poorer' and are 'kept in the dark'. The discussed tensions concerning human identity contained accounts of Davies and Macnaghten's counter narratives 'messing with nature' and 'be careful what you wish for'. Besides intervention by the dialog facilitator, adaptations to the dialog format itself might also be able to remedy the designer fallacy. In order to encourage a critical mode at an earlier stage of the dialog, one could think of (1) paying more attention to the non-linearity of technology development and technology uptake at the start of the session, providing concrete and illustrative examples, (2) letting participants write both utopic and dystopic story fragments in the writing exercise and collectively reflect on when and why utopic becomes dystopic, or (3) not letting participants imagine stories about their own prototype, but about a prototype created by others. In addition, more explicit attention may be focused on the participants' use of comparison, as references to other technologies may not only be used to make sense of the unfamiliar, but also serve a rhetorical role to push certain narratives and framings into the discussion [44].

Second, despite our intention not to get stuck in discussion on hazardous effects of nano particles and nanostructures, we were surprised to see that these topics-particularly environmental risks-were barely discussed at all. In previous dialogs, lay publics did voice these issues as prominent concerns-e.g., [45, 46] - and in our evaluation questionnaire, several participants also indicated that they would have liked the issue to be part of the discussion. The absence of the issue in the dialogical exchanges could be a result of 
our focus on nano-enabled applications, encouraging participants to concentrate on the products that nanotechnologies could enable instead of the 'nano' behind these products. Also, environmental hazards might not be as pressing in the field of nanomedicine and BCIs compared with other nanotechnology application fields, including nanotextiles. In our nanotextile dialogs, we may not have heard much explicit discussion about environmental risks, but certainly observed a considerable number of remarks that participants made about the environmentalfriendliness of their nanotextile prototypes. This suggests that participants do attribute a certain value to environmental care in nanotextile development.

Third, our analysis showed that while some prototypes closely resembled the described developments on the information cards (e.g., a biosensor measuring an individual's nutrition levels), the scope of freedom of our format to imagine one's own future object and the societal context in which it is embedded bears the risk of producing scenarios that seem too detached from current realities (e.g., nano-enabled BCI devices allowing telepathic communication). Various scholars, among whom prominently Nordmann and Rip [47], voiced their unease with this level of speculation, as it would focus ethical debates on far-fetched concerns at the cost of more relevant issues that accompany near-future developments. In line with Grunwald [48], we argue that more speculative approaches-such as employed in our format-might indeed not be useful for engagement directed at concrete action or decisionmaking. However, situated prototyping could be valuable as a form of 'explorative philosophy', in which citizens 'prepare for possibly coming debates' [39, p. 96-97] and scrutinize new questions that might become relevant in time. In doing so, we do consider it helpful to provide participants with input material that is informed by current developments in nanotechnology (e.g., our 'information cards') or grounded in historical knowledge on the dynamics between technology and society (e.g., our 'impact cards' for story-writing).

Lastly, we would like to draw attention to the critical role of the facilitator to stimulate and enrich contextualization processes. As Van der Meij et al. [49] point out in their case study on the use of an innovative playful tool for inclusive reflection on synthetic biology, facilitators help to reduce participants' insecurity during creative and imaginative exercises, make the ambiguous materials provided more productive, and stimulate deeper reflection by asking 'why?' questions. Our observations and debriefs with dialog facilitators indeed showed that during prototyping and story-writing, participants needed confirmation and encouragement to use their imagination. Furthermore, it seemed that merely providing ambiguous material during prototyping and story-writing did not always suffice to let participants explore ambiguities in relation to nanotechnology in their full breadth (see our comments on the 'designer fallacy'). The facilitators' explicit guiding questions during the plenary discussion helped participants to make more productive use of ambiguous materials in their contextualization process. We must also note that the facilitation style strongly influenced the richness of the plenary discussion. Some facilitators mainly focused on collecting input (i.e., values, needs, concerns), whereas others focused on the story behind the input, thereby acquiring more in-depth insight. Time constraints as well as level of experience with facilitation, may have been of influence here. We thus stress the importance of sufficient time for a skillfully facilitated plenary discussion. As facilitation is never a neutral endeavor $[6,50,51]$, we encourage explicit awareness about facilitation style by those using the situated speculative prototyping format, particularly when gathering qualitative data.

\section{Conclusion}

Our public engagement experiment has shown that the use of situated speculative prototyping has the potential to help participants contextualize new and emerging technologies, such as nanotechnology, and therefore becomes a good extension to static risk-benefit or acceptance-rejection dichotomies. The use of physical material and narration helps to trigger new questions and unfold new situated understandings of nanotechnology and its implications, without relying on mere abstract and cognitive forms of exploration and exchange. Yet, at the same time, the methodology has certain pitfalls that should be dealt with carefully. One of the most prominent pitfalls is the risk of the 'designer fallacy' that could reproduce technoscientific framings and obstruct critical reflection on technological directions and implications if not treated with caution. Designing an engagement format is a delicate balancing act, with each choice 
having both its benefits and its price. It is for this reason that Davies et al. [12] argue that the power of deliberative societies does not reside in creating ideal-type engagement processes, but in having a diversified spectrum of engagement formats and opportunities that together constitute a more open and inclusive research and innovation system, such as promoted by RRI. Within such a spectrum, we see potential for situated speculative prototyping in the realm of informal engagement initiatives with an explorative approach to new and emerging technologies. We nevertheless stress that explicit coupling of prototyping activities with guidance into a critical mindset remains a crucial point of attention to prevent the format from being used as a mere tool for public acceptance of technology.

Supplementary Information The online version contains supplementary material available at https://doi.org/10.1007/ s11569-020-00382-4.

\begin{abstract}
Acknowledgments Special thanks go to the local learning institutions that organized and hosted the dialog sessions and helped us to gather the dialog data. We would also like to express our gratitude to all NANO2ALL project partners who supported us in creating and implementing the format in practice. We thank our colleague Anouk Heltzel for contributing to the initial round of data analysis that took place right after the dialog sessions and that were integrated in the result section of this paper. Lastly, we greatly valued the reviewers' comments and suggestions that helped us to improve and fine-tune this paper.
\end{abstract}

Funding This research took place in the context of the NANO2ALL project. This project has received funding from the European Union's Horizon 2020 research and innovation program under grant agreement no 685931. This document reflects only the author's view and the Commission is not responsible for any use that may be made of the information it contains.

\section{Declarations}

Conflict of Interest The authors declare that they have no conflict of interest.

Open Access This article is licensed under a Creative Commons Attribution 4.0 International License, which permits use, sharing, adaptation, distribution and reproduction in any medium or format, as long as you give appropriate credit to the original author(s) and the source, provide a link to the Creative Commons licence, and indicate if changes were made. The images or other third party material in this article are included in the article's Creative Commons licence, unless indicated otherwise in a credit line to the material. If material is not included in the article's Creative Commons licence and your intended use is not permitted by statutory regulation or exceeds the permitted use, you will need to obtain permission directly from the copyright holder. To view a copy of this licence, visit http://creativecommons.org/licenses/by/4.0/.

\section{References}

1. Owen R, Macnaghten P, Stilgoe J (2012) Responsible research and innovation: from science in society to science for society, with society. Sci Public Policy 39:751-760. https://doi.org/10.1093/scipol/scs093

2. Felt U, Wynne B, Al. E (2007) Taking European knowledge society seriously. Report of the expert group on science and governance to the Science, Economy and Society Directorate, Directorate-General for Research, European Commission. Brussels

3. Von Schomberg R (2013) A vision of responsible research and innovation. In: Owen R, Bessant J, Heintz M (eds) Responsible Innovation: Managing the Responsible Emergence of Science and Innovation in Society. Wiley, Chichester, pp 51-74

4. Stilgoe J, Owen R, Macnaghten P (2013) Developing a framework for responsible innovation. Res Policy 42:15681580. https://doi.org/10.1016/j.respol.2013.05.008

5. Swierstra T, Rip A (2007) Nano-ethics as NESTethics: patterns of moral argumentation about new and emerging science and technology. Nanoethics 1:3-20. https://doi.org/10.1007/s11569-007-0005-8

6. Selin $\mathrm{C}$, Rawlings $\mathrm{KC}$, de Ridder-Vignone $\mathrm{K}$ et al (2017) Experiments in engagement: designing public engagement with science and technology for capacity building. Public Underst Sci 26:634-649. https://doi. org/10.1177/0963662515620970

7. Davies S, Mccallie E, Simonsson E et al (2009) Discussing dialogue: perspectives on the value of science dialogue events that do not inform policy. Public Underst Sci 18:338-353. https://doi.org/10.1177/0963662507079760

8. Krabbenborg L, Mulder HAJ (2015) Upstream public engagement in nanotechnology. Sci Commun 37:452-484. https://doi.org/10.1177/1075547015588601

9. Ribeiro BE, Smith RDJ, Millar K (2017) A mobilising concept? Unpacking academic representations of responsible research and innovation. Sci Eng Ethics 23:81-103. https://doi.org/10.1007/s11948-016-9761-6

10. Dijkstra AM, Critchley CR (2016) Nanotechnology in Dutch science cafés: public risk perceptions contextualised. Public Underst Sci 25:71-87. https://doi. org/10.1177/0963662514528080

11. Lehoux P, Miller FA, Grimard D, Gauthier P (2017) Anticipating health innovations in 2030-2040: where does responsibility lie for the publics? Public Underst Sci 27:276-293. https://doi.org/10.1177/0963662517725715

12. Davies SR, Selin C, Gano G, Pereira ÂG (2012) Citizen engagement and urban change: three case studies of material deliberation. Cities 29:351-357. https://doi.org/10.1016/j. cities.2011.11.012 
13. Kuzmanovic M, Gaffney N (2016) Enacting futures in postnormal times. Futures 86:107-117. https://doi. org/10.1016/j.futures.2016.05.007

14. Roeser S, Alfano V, Nevejan C (2018) The role of art in emotional-moral reflection on risky and controversial technologies : the case of BNCI. Ethical Theory Moral Pract 21:275-289. https://doi.org/10.1007/s10677-018-9878-6

15. Kurath M, Gisler P (2009) Informing, involving or engaging? Science communication, in the ages of atom-, bio- and nanotechnology. Public Underst Sci 18:559-573. https://doi.org/10.1177/0963662509104723

16. Braun K, Könninger S (2018) From experiments to ecosystems? Reviewing public participation, scientific governance and the systemic turn. Public Underst Sci 27:674-689. https://doi.org/10.1177/0963662517717375

17. Wynne B (2007) Public participation in science and technology: performing and obscuring a politicalconceptual category mistake. East Asian Sci Technol Soc 1:99-110. https://doi.org/10.1215/s12280-007-9004-7

18. Felt U, Schumann S, Schwarz CG (2015) (Re) assembling natures, cultures, and (nano)technologies in public engagement. Sci Cult (Lond) 24:458-483. https://doi.org/10.1080/09505431.2015.1055720

19. Davies SR (2011) How we talk when we talk about nano: the future in laypeople's talk. Futures 43:317-326. https:// doi.org/10.1016/j.futures.2010.07.003

20. Felt U, Schumann S, Schwarz CG, Strassnig M (2014) Technology of imagination: a card-based public engagement method for debating emerging technologies. Qual Res 14:233-251. https://doi.org/10.1177/1468794112468468

21. Bleecker J (2009) Design Fiction: A short essay on design, science, fact and fiction

22. Bosch T (2012) Sci-Fi writer Bruce Sterling explains the intriguing new concept of Design Fiction. Slate

23. Lindley J, Coulton P (2015) Back to the future: 10 years of design fiction. In: Proceedings of the 2015 British HCI Conference. pp 210-211

24. Dunne A, Raby F (2013) Speculative everything: design, fiction, and social dreaming. MIT Press, Cambridge, MA

25. Auger J (2012) Why robot?: speculative design, the domestication of technology and the considered future. Royal College of Art, London

26. Forlano L, Mathew A (2014) From design fiction to design friction: speculative and participatory design of valuesembedded urban technology. J Urban Technol 21:7-24

27. Heidingsfelder ML, Schütz F, Kaiser S (2016) Expanding participation: participatory design in technology agendasetting. 25-28. https://doi.org/10.1145/2948076.2948087

28. Rozendaal MC, Heidingsfelder ML, Kupper F (2016) Exploring embodied speculation in participatory design and innovation. In: Proceedings of the 14th Participatory Design Conference: Short Papers, Interactive Exhibitions, Workshops-Volume 2. pp 100-102

29. Baumann K, Stokes B, Bar F, Caldwell B (2017) Infrastructures of the imagination: community design for speculative urban technologies. In: Proceedings of the 8th International Conference on Communities and Technologies. Chicago, pp 266-269

30. Heidingsfelder M, Kimpel K, Best K, Schraudner M (2015) Shaping future - adapting design know-how to reorient innovation towards public preferences. Technol Forecast
Soc Change 101:291-298. https://doi.org/10.1016/j.techfore. 2015.03.009

31. Boenink M, Swierstra T (2010) Anticipating the interaction between technology and morality: a scenario study of experimenting with humans in bionanotechnology. Stud Ethics Law Technol 4(2):1-38. https://doi.org/10.2202/1941-6008.1098

32. MG Meij van der JEW Broerse F Kupper 2017 Conceptualizing playfulness for reflection processes in responsible research and innovation contexts: a narrative literature review J Responsible Innov $121 \mathrm{https}: / /$ doi. org/10.1080/23299460.2017.1326258

33. Krabbenborg L (2013) Dramatic rehearsal on the societal embedding of the lithium chip. In: Van der Burg S, Swierstra T (eds) Ethics on the laboratory floor. Palgrave Macmillan, New York, pp 168-183

34. Kupper F (2017) The theatrical debate: experimenting with technologies on stage. In: Van de Poel I, Asveld L, Mehos D (eds) New Perspectives on Technology in Society. Routledge, London, pp 80-102

35. Boenink M (2010) Imagining the future: how vignettes and scenarios might improve ethical reflection on synthetic biology for health purposes. In: Szebik I (ed) Ethics and clinical applications of authentic biology: an interdisciplinary dialogue. SYBHEL project, Bilbao, pp 55-64

36. Braun V, Clarke V (2006) Using thematic analysis in psychology. Qual Res Psychol 3:77-101

37. VERBI Software (2018) MAXQDA 2018

38. Broms L, Wangel J, Andersson C (2017) Sensing energy: forming stories through speculative design artefacts. Energy Res Soc Sci 31:194-204. https://doi.org/10.1016/j. erss.2017.06.025

39. NANO2ALL (2018) Responsible Innovation Agendas at national level (project deliverable)

40. Davies SR, Macnaghten P (2010) Narratives of mastery and resistance: lay ethics of nanotechnology. Nanoethics 4:141151. https://doi.org/10.1007/s11569-010-0096-5

41. Horlick-Jones T, Walls J, Kitzinger J (2007) Bricolage in action: learning about, making sense of, and discussing, issues about genetically modified crops and food. Heal Risk Soc 9:83-103. https://doi.org/10.1080/13698570601181623

42. Macnaghten P, Davies SR, Kearnes M (2019) Understanding public responses to emerging technologies: a narrative approach. J Environ Policy Plan 21:504-518. https://doi. org/10.1080/1523908X.2015.1053110

43. Ihde D (2006) The designer fallacy and technological imagination. In: Dakers J (ed) Defining Technological Literacy. Palgrave Macmillan, New York, pp 121-131

44. Schwarz-Plaschg C (2016) Nanotechnology is like ... The rhetorical roles of analogies in public engagement. Public Underst Sci 27:153-167. https://doi.org/10.1177/ 0963662516655686

45. Van Est R, Walhout B, Rerimassie V et al (2012) Governance of nanotechnology in the Netherlands, informing and engaging in different social spheres. Aust J Emerg Technol Soc 10:6-26

46. Carvalho A, Nunes JA (2013) Technology, methodology and intervention: performing nanoethics in Portugal. Nanoethics 7:149-160. https://doi.org/10.1007/s11569-013-0175-5

47. Nordmann A, Rip A (2019) Mind the gap revisited. Nat Nanotechnol 4:273-274. https://doi.org/10.1038/ s41587-019-0141-z 
48. Grunwald A (2010) From speculative nanoethics to explorative philosophy of nanotechnology. Nanoethics 4:91101. https://doi.org/10.1007/s11569-010-0088-5

49. van der Meij MG, Heltzel AALM, Broerse JEW, Kupper F (2018) Frame reflection lab: a playful method for frame reflection on synthetic biology. Nanoethics 12:155-172. https://doi.org/10.1007/s11569-018-0318-9

50. Escobar O, Faulkner W, Rea HJ (2014) Building capacity for dialogue facilitation in public engagement around research. J Dialogue Stud 2:87-111
51. Carvalho A, Nunes JA (2018) Assembling upstream engagement: the case of the Portuguese Deliberative Forum on nanotechnologies. Nanoethics 12:99-113. https://doi. org/10.1007/s11569-018-0314-0

Publisher's Note Springer Nature remains neutral with regard to jurisdictional claims in published maps and institutional affiliations. 